\title{
Baldıran Otu Zehirlenmesine Bağlı Solunum Depresyonu Gelişen Bir Olgu Sunumu
}

\author{
Respiratory Failure Due To Hemlock Intoxication; A Case Report
}

\author{
Nihal AKÇAY, Ayşe İrem SOFUOĞLU, Ülkem KOÇOĞLU BARLAS, Güner ÖZÇELIK, \\ Kübra BOYDAĞ GÜVENÇ, Esra ŞEVKETOĞLU
}

SBÜ. İstanbul Bakırköy Sadi Konuk, Eğitim Araştırma Hastanesi, Çocuk Yoğun Bakım Kliniği, İstanbul, Türkiye

\begin{abstract}
ÖZ
Baldıran otu (Conium maculatum) zehirli bir bitkidir. Yanlışlıkla alımı sonucu merkezi sinir sistemi depresyonu, solunum yetersizliği, akut rabdomiyoliz, akut böbrek yetersizliği ve hatta ölüm meydana gelebilir. Bu zehirlenmede tedavi destekleyicidir. Burada, baldıran otu alımı sonrası solunum arresti ile acil servise başvuran ve beş dakika süren kardiyopulmoner resüsitasyon sonrası entübe olarak çocuk yoğun bakım ünitemize transfer edilen 3 yaşında bir kız olgu sunulmaktadır. Hastaya, Ulusal Zehir Danışma Merkezi tarafından tam barsak irrigasyonu önerilmesi üzerine Golytely kullanılarak gaita çıkışı takip edildi. Rektal akıntı berrak bir hale gelene kadar her 15 dakikada bir 125 ml Golytely nazogastrik sonda ile enteral uygulandı. Toksik metabolitleri uzaklaștırmak amacıyla terapötik plazma değișimi bir kez yapıldı. Karaciğer ve böbrek fonksiyon testleri yakın aralıklarla izlendi. Aspirasyon pnömonisi de gelişen hasta altı gün entübe olarak izlendikten sonra ekstübe edildi. Onuncu günde sekelsiz olarak taburcu edildi. Bu olgu, çevredeki bazı bitkilerin günlük tüketilen sebzelere benzerlikleri nedeni ile yanlışlıkla alım sonucu ciddi zehirlenme bulgularına ve hatta ölüme neden olabileceklerini vurgulamak amacı ile sunuldu
\end{abstract}

Anahtar Sözcükler: Baldıran otu, Conium maculatum, Terapötik plazma değişimi

\begin{abstract}
Hemlock (Conium Maculatum) is a poisonous plant. Ingestion by mistake can cause central nervous system depression, respiratory failure, acute rhabdomyolysis, acute renal failure or even death. The treatment is supportive. In this case report, we present a three year-old girl who was brought to an emergency department with respiratory arrest, after ingestion of hemlock. Cardiopulmonary resuscitation was performed for 5 minutes and then she was transferred to our pediatric intensive care unit as in intubated state. Whole bowel irrigation was suggested by National Poison Counselling Center and $125 \mathrm{ml}$ Golytely was used for bowel irrigation in every 15 minutes via nasogastric tube, until rectal drainage became clear. Therapeutic Plasma Exchange was performed once so as to remove toxic metabolites. Liver and renal function tests were closely monitored. The patient was intubated for 6 days because of aspiration pneumoniae and then extubated. She was discharged on day 10 with no sequelae. This case was reported to emphasize that some plants can be mistaken for commonly used vegetables because they look similar and can cause serious poisoning and can even cause death.
\end{abstract}

Key Words: Hemlock, Conium maculatum, Therapeutic plasma exchange

Nihal AKÇAY

Ülkem KOÇOĞLU BARLAS

Esra ȘEVKETOĞLU

Güner ÖZCELIK

Kübra BOYDAĞ GÜVENC

Ayșe Irem SOFUOĞLU
:0000-0002-8273-2226

0000-0001-7445-5858

0000-0002-8330-2877

0000-0001-7694-2860

:0000-0003-3881-6980

0000-0002-3757-912X
Çıkar Çatışması / Conflict of Interest: : Tüm yazarlar adına, ilgili yazar çıkar çatıșması olmadığını belirtir.

Finansal Destek / Financial Disclosure: Yazarlar bu olgu için finansal destek almadıklarını beyan etmişlerdir.

Onay / Confirmation: Kayıt sırasında veliler tarafından araștımaya katıım için bilgilendirilmiş bir onay imzalanmıştır.

Atıf yazım şekli / How to cite : Akçay N, Koçoğlu Barlas Ü, Şevketoğlu E, Özçelik G, Boydağ Güvenç K, Sofuoğlu Ail. Baldıran Otu Zehirlenmesine Bağl Solunum Depresyonu Gelișen Bir Olgu Sunumu. Türkiye Çocuk Hast Derg 2021; 15: 84-86.

Ek bilgi / Additional information: Sunulduğu kongre: 16. Ulusal Çocuk Acil Tıp ve Yoğun Bakım Kongresi, Antalya, Ekim 2019
Yazışma Adresi / Correspondence Address:

Nihal AKÇAY

SBÜ. İstanbul Bakırköy Sadi Konuk, Eğitim Araştırma Hastanesi,

Çocuk Yoğun Bakım Kliniği, İstanbul, Türkiye

E-posta: drnihalakcay@gmail.com
Geliș tarihi / Received : :27.05.2020 Kabul tarihi / Accepted : 02.07.2020 Elektronik yayın tarihi $\quad: 20.10 .2020$ Online published

DOI: 10.12956/tchd.745282 


\section{Giriș}

Baldıranotu (Conium maculatum), Antartika hariç tüm kıtalarda bulunan Apiaceae ailesindeki bir bitkidir. Zehirlenme nispeten nadirdir, ancak insidansı dünya çapında bölgesel farklılık göstermektedir. Avrupa ve özellikle Akdeniz ülkelerinde daha yaygındır. Görünüşü ve yetiştiği bölge itibariyle, kazayağı otu ile de karışabilmektedir (1).

Bu bitkinin yaygın dağılımı ve diğer yenilebilir bitkilere görsel benzerliği nedeniyle, oral yoldan alınmasına bağlı zehirlenmeler görülmüştür. Bu vakalarda kas güçsüzlüğüne bağlı solunum yetmezliği gelişebilmektedir. Bu olgu sunumu ile baldıran otuna bağlı solunum arresti gelişen bir hastanın postarrest yönetimine dikkat çekilmesi amaçlanmıştır.

\section{OLGU SUNUMU}

Üç yaşında kız hasta kardiyopulmoner arrest nedeniyle resüsite edildikten sonra entübe şekilde çocuk yoğun bakım ünitemize alındı. Öyküsünden ailesi tarafindan kazayağı otu olduğu düşünülerek toplanıp pişirilen yemeği yedikten yaklașık iki saat sonra kusma şikâyetinin başladığı ve sonrasında bilincinin kapandığı öğrenildi (Resim 1). Hastanın götürüldüğü dış merkezde kardiyopulmoner arrest olduğu saptanarak yaklaşık beș dakika süre ile kardiyopulmoner resüsitasyon yapıldığı (iki kez adrenalin $0.01 \mathrm{mg} / \mathrm{kg}$ intravenöz puşe) ve bu süre içerisinde entübe edildiği öğrenildi.

Olgunun ünitemizdeki ilk fizik muayenesinde genel durumu kötü, bilinci kapalı, Glasgow koma ölçeği 6 (Göz açma: 1, Sözel: 1, Motor: 4), kan basıncı 84/47 (58) mmHg, kalp tepe atımı 156 /dk, vücut sıcaklığı $36.5{ }^{\circ} \mathrm{C}$, solunum sayısı $37 / \mathrm{dk}$ olduğu gözlendi. Pupilleri dilate ve ışık refleksi mevcuttu. Diğer sistem muayeneleri doğaldı.

Hastanın laboratuar tetkiklerinde; hemoglobin 10.1 (10.2-12.7) g/dL, lökosit 15890 (4860-13180)/mm³, glukoz 221 (74-106) $\mathrm{mg} / \mathrm{dL}$, üre 20 (17-43) mg/dL, kreatinin $0.16(0.19-0.41) \mathrm{mg} /$ dL sodyum potasyum 140 (136-145) mmol/L, 2.99 (3.5-5.1) mmol/L, klor 107 (98-107) mmol/L, kalsiyum 9 (9.2-10.5) mg/ dl, fosfor 2.3 (4.1-6.3) mg/dl, magnezyum 1.46 (1.6-2.6) mg/dl, aspartat aminotransferaz 211 (0-32) $\mathrm{U} / \mathrm{L}$, alanin aminotransferaz 100 (0-33) U/L, CK: 88 (0-170) U/L, protrombin zamanı 15.9 (1115) s'di. Kan gazında pH 7.24 (7.35-7.45), pCO2 57.5 (35-45) $\mathrm{mmHg}$, laktat 2.8 (0.5-2) mmol/L, bikarbonat 21 (22-26) mmol/L olduğu saptandı. Çekilen EKG'si normaldi. Akciğer grafisinde aspirasyonu düşündüren infiltratif görünüm mevcuttu. Hastanın yediği otun zehir danışma merkezine danışılarak baldıran otu olduğu öğrenildi. Tam barsak irrigasyonu önerildi. Hastadan toksik metabolitleri uzaklaştırmak amacıyla terapötik plazma değişimi bir kez yapıldı. Karaciğer ve böbrek fonksiyon testlerinin yakın aralıklarla izlenmesi planlandı. Golytely kullanılarak gaita

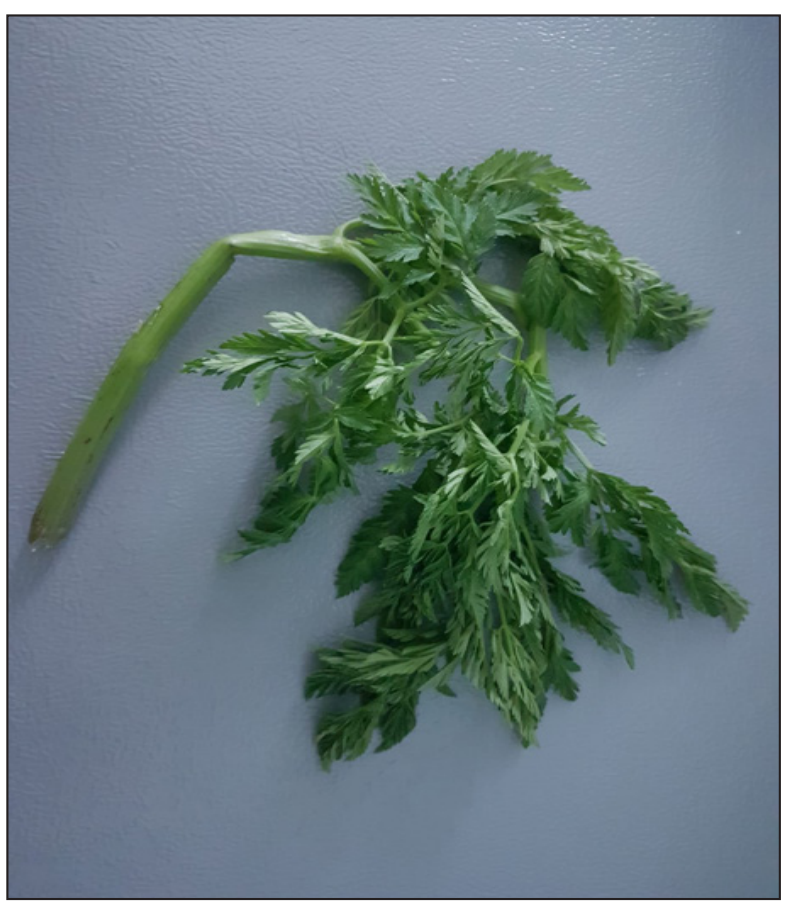

Resim 1: Hastanın zehirlenmesine neden olan baldıran otu. Hastanın zehirlenmesine neden olan baldıran otu (Kazayağı otu olduğu düşünülerek toplanmış).

Çıkışı takip edildi, rektal akıntı berrak bir hale gelene kadar her 15 dakikada $125 \mathrm{ml}$ Golytely nazogastrik sonda ile enteral uygulandı. Akciğer grafisinde aspirasyonu düşündüren infiltratif görünüm olması nedeniyle ampisilin sulbaktam antibiyoterapisi bașlandı. Mekanik ventilasyon intiyacı tedrici olarak azalan ve cihaz ayarları düşülen hasta, yatışının altıncı gününde ekstübe edilerek noninvaziv mekanik ventilasyona alındı. Yatışının 10. gününde hasta sekelsiz olarak çocuk servisine devredildi.

\section{TARTIŞMA}

Conium maculatum zehirlenmesi; coniceine, coniine, $\mathrm{N}$-metil coniine, conhidrine ve psödoconhydrine gibi nikotinik etkileri olan piperidin alkaloid içeriği nedeniyle meydana gelir. Bitkinin her kısmı toksik olsa da, en yüksek alkaloid konsantrasyonu tohumlarında bulunur (2). Ataksi ve baș ağrısı, zehirlenmenin erken aşamasında gözlenen semptomlardır. Bitkinin otonom gangliyonlar üzerindeki etkileri nedeniyle tükürük sekresyonunda artış, taşikardi ve pupiller dilatasyon gelişir. Kolinerjik uyaranların artması nedeniyle bazı hastalarda kas güçsüzlüğü veya felci, bradikardi ve merkezi sinir sistemi depresyonu gelişebilir (3). Conium maculatum zehirlenmesinin bir sonucu olarak rabdomiyoliz ve akut böbrek yetmezliği de rapor edilmiştir (4). Piperidin alkaloidlerinin her biri bir tür periferal nörotoksindir; nörotoksinler nöromüsküler kavşaklarda kürar benzeri etki gösterir ve otonom gangliyonlarda nikotinik etki yaratır (5). Akut olay şiddetlidir ve hayatı tehdit eder, ancak tedavi derhal sağlanırsa sağkalım oranı yüksektir. Iyileșme hızıdır, genellikle 
sadece birkaç gün sürer (6). Bizim hastamızda da solunum kaslarının güçsüzlüğüne bağlı solunum arresti gelişmiş ve postarrest yoğun bakım takibinde de taşikardisi, pupiller dilatasyonu ve sekresyon artışı mevcuttu.

Bu toksinin tedavisi için spesifik bir antidot yoktur. Bu nedenle, semptomatik tedavi ana tedavidir. Temel yaşam desteği sağlanmalı, ardından emilimi azaltmak için gastrik lavaj ve barsak irrigasyonu uygulanmalıdır. SIvı tedavisi intravenöz yolla uygulanmalıdır. Konvülziyon gelişirse benzodiazepinler veya barbitüratlar kullanılmalıdır. Rabdomiyoliz veya miyoglobinüri olması durumunda sıvı takviyesi ve idrar alkalinizasyonu sağlanmalıdır (7). Yoğun bakım ünitesi takibi sırasında yakın biyokimyasal inceleme ve elektrolit izlemi yapılmalıdır. Ölüm, esas olarak solunum yetmezliği ve solunum kaslarındaki güçsüzlük nedeniyle gelişen solunum arrestine bağlı oluşur bunun için havayolunun devamllığı sağlanmalı ve gerekirse mekanik ventilasyon desteğinde bulunulmalıdır (8). Bizim hastamız da kardiyopulmoner arrest geliştiği için mekanik ventilasyonda takip edildi. Mide lavajı yapıldıktan sonra Golytely kullanılarak gaita çıkışı takip edildi, rektal akıntı berrak bir hale gelene kadar nazogastrik sonda ile her 15 dakikada 125 $\mathrm{ml}$ Golytely enteral uygulandı. Birçok zehirlenmede de tam barsak irrigasyonu önerilmektedir (9). Bizim hastamızda toksik metabolitleri uzaklaştırmak amacıyla terapötik plazma değişimi bir kez yapıldı, literatürde daha önce plazma değişimi yapılan vaka bulunmamaktadır.

Sonuç olarak; zehirli bitkilerin yanlışlıkla tüketilmesinden kaynaklanan zehirlenmelerin çoğu minimal toksisiteye sahip olsa da, baldıran otu zehirlenmesi ölümcül olabilir. Sağlık çalışanları, açıklanamayan solunum yetmezliği ve koma ile başvuran hastalarda baldıran otu zehirlenmesi olasılığını akıllarında bulundurmalıdır. Terapötik plazma değişimi erken dönemde yapılması toksik metabolitlerin uzaklaştııımasını sağlar.

\section{KAYNAKLAR}

1. Cortinovis C, Caloni F. Alkaloid-containing plants poisonous to cattle and horses in Europe. Toxins 2015;7:5301-7.

2. Leete EB. Becoming a hospice volunteer. Am J Hosp Palliat Care 1994;11:27-32.

3. Ferah AU, Dilek MO, Ercument Y, Oktay D. Hemlock poisoning (case report): die like socrates. Resuscitation 2006;70:337.

4. Rizzi D, Basile C, Di Maggio A, Sebastio A, Introna F Jr, Rizzi $\mathrm{R}$, et al. Clinical spectrum of accidental hemlock poisoning: neurotoxic manifestations, rhabdomyolysis and acute tubular necrosis. Nephrol Dial Transplant 1991;6:939-43.

5. Krenzelok EP, Jacobsen TD, Aronin JM. Hemlock ingestions: The most deadly plant exposures. J Toxicol Clin Toxicol 1996;34:601-2.
6. Karakasi MV, Tologkos S, Papadatou V, Raikos N, Lambropoulou M, Pavlidis P. Conium maculatum intoxication: Literature review and case report on hemlock poisoning. Forensic Sci Rev 2019;31:23-36.

7. Froberg B, Ibrahim D, Furbee RB. Plant poisoning. Emerg Med Clin North Am 2007;25:375-433.

8. West PL, Horowitz BZ, Montanaro MT, Lindsay JN. Poison hemlock-induced respiratory failure in a toddler. Pediatr Emerg Care 2009;25:761-3.

9. Thanacoody R, Caravati EM, Troutman B, Höjer J, Benson B, Hoppu K, et al. Position paper update: whole bowel irrigation for gastrointestinal decontamination of overdose patients. Clin Toxicol (Phila) 2015;53:5-12. 